\title{
Educação contextualizada no letramento escolar: um olhar sobre a EJA
}

\author{
Contextualized education in the school literacy: a look at Youth and Adult \\ Education
}

\author{
LIMA, Fábio Ronne de Santana. Mestre em Educação, Cultura e Territórios \\ Semiáridos/Licenciado em Letras \\ Universidade do Estado da Bahia - campus III. Rua Edgar Chastinet, s/n, São Geraldo - Juazeiro - Bahia - Brasil. \\ CEP: 48.905-680 / Telefone: (87) 3611-6483 / E-mail: fabioronne@hotmail.com
}

\section{RESUMO}

O objetivo deste artigo é apresentar a prática da educação contextualizada no letramento escolar considerando-se a diversidade cultural na sala de aula no semiárido brasileiro. É uma pesquisa de abordagem qualitativa-descritiva e foi desenvolvida em uma escola de zona rural no município de Petrolina/PE. 0 método escolhido foi o etnográfico e foram utilizadas as seguintes técnicas de procedimento: a observação participante, o diário de bordo e a gravação de aulas e entrevistas informais com discentes e o docente. 0 trabalho foi realizado em uma turma de quarta fase de Educação de Jovens e Adultos com foco em quatro colaboradores: três estudantes e o professor de língua portuguesa da turma. Os resultados mostram que o letramento não pode ser reduzido às ações de decodificação, uma vez que, como os alunos têm consciência de sua cultura e almejam se tornar mais atuantes e autônomos em sua sociedade, o uso da contextualização pelos professores melhora não só o letramento mas o aprendizado escolar de modo geral porque usa a realidade dos alunos como subsídio para o ensino.

Palavras-chave: Semiárido brasileiro, Práticas de letramento, Contextualização

\begin{abstract}
The aim of this article is to present contextualized education in school reading and writing practices due to the cultural diversity in the classroom in the Brazilian semi-arid region. It is a qualitativedescriptive research and it was developed in a rural school in the municipality of Petrolina/PE. The selected method was ethnographic and the following procedure techniques were used: participant observation, logbook, and recording of classes and informal interviews with students and teachers. The study was carried out in a fourth-phase class of Youth and Adult Education with a focus on four participants: three students and the Portuguese language teacher of the class. The results show that reading and writing skills cannot be reduced to decoding actions, since, as students are aware of their culture and aim to become more active and autonomous in their society, the use of contextualization by teachers improves not only reading and writing skills but school learning in general because it uses the reality of students as a subsidy for teaching.
\end{abstract}

keywords: Brazilian semi-arid region, Reading and writing practices, contextualization 


\section{Introdução}

Historicamente, o acesso à escola foi um direito reservado apenas a uma pequena parcela da população brasileira: à elite, e mais especificamente aos homens, e depois mulheres aristocratas. Todavia, somente a partir do século 19, no Brasil, houve um avanço e democratização em relação a isto, ao passo em que foi compreendido que a educação é um direito humano, conferido a todos, independentemente da cor, do gênero e da classe dos indivíduos, o que garantiu à educação um status de políticas públicas, estabelecendo às classes populares "munição" para serem mais resistentes e mais fortes em relação à desigualdade.

$\mathrm{O}$ grande índice de analfabetismo e a evasão escolar emergida após a possibilidade de inserção da população não abastada financeiramente causou uma instabilidade na educação brasileira: não foi a questão da entrada de pessoas mais pobres na escola que determinou a queda, mas a postura da instituição em relação às novas culturas que adentram no espaço, conforme salientam Saviani (1985) e Soares (1999).

Este artigo envolve uma investigação de cunho etnográfico com descrição densa acerca da realidade dos estudantes da Educação de Jovens e Adultos (EJA). Essa modalidade de ensino deve ser tomada como um direito à cidadania e a efetiva participação dessas pessoas na estrutura política, econômica e social do Brasil (CAPUCHO, 2012). A descrição densa da sala de aula e dos colaboradores observados é necessária para que se percebam as histórias, os traços e as identidades desses estudantes que tiveram que escolher entre um direito e uma necessidade.

A tese desenvolvida neste trabalho é baseada em Freire $(1967,2002)$, pois acredita-se que, no processo de ensino, as experiências dos estudantes precisam ser consideradas. Esse autor desenvolve seu pensamento a partir de reflexões feitas por temáticas sugeridas pelos próprios integrantes desses grupos populares, o que faz o autor concluir que todo homem é um ser histórico-cultural. Além desta base, é exposto o conceito de Educação Contextualizada, perspectiva que pautada na abordagem freireana, desenvolve a uma prática também alicerçada na liberdade e protagonismo dos educandos.

Essa perspectiva de educação envolve a realidade dos sujeitos aprendentes (OLIVEIRA; REIS, 2017), logo é pertinente observar que uma análise que parte do Semiárido. É coerente, portanto, entender os traços culturais envolvidos nessa nova direção da educação: propor ao estudante o lugar de centro na aprendizagem, de fato, a partir da contextualização e da adequação na transposição didática.

A partir de uma descrição de cunho etnográfico (LÓPEZ, 1999) e utilizando técnicas específicas para este método, pautadas na análise interpretativista (BORTONI- RICARDO, 2008), os resultados apontam para uma contribuição da Educação Contextualiza no letramento escolar pela concepção intercultural. Assim, é necessário que sejam discutidos os vieses teóricos que embasarão esses resultados.

Inicialmente, é importante que se compreenda que educar é um ato humano. Freire 
LIMA, F. R. S.

Educação contextualizada no letramento escolar: um olhar sobre a EJA

(1967) evidencia isso e suas palavras já direcionam a uma necessidade contextual da prática:

Não há educação fora das sociedades humanas e não há homem no vazio. 0 esforço educativo que desenvolveu o Autor e que pretende expor neste ensaio, ainda que tenha validade em outros espaços e em outro tempo, foi todo marcado pelas condições especiais da sociedade brasileira. Sociedade intensamente cambiante e dramaticamente contraditória. (FREIRE, 1967, p. 35)

Essa abordagem implica diretamente no modelo educativo padronizado e homogêneo que o Brasil tem seguido. Entretanto, o que se vê são realidades plurais que estão convivendo nas ruas, nas empresas, nas casas, nas escolas. Diante dessa condição diversa, entende-se que cada pessoa tem a sua filosofia inerente, e, como consequência, na escola, estas filosofias são entrecruzadas; portanto, o aparato ideológico da instituição escolar torna-se raso para suprir as demandas que o homem em sua existência propõe. Esse viés plural, heterogêneo e descolonizado embasa as discussões de uma educação contextualizada.

Martins (2004) apresenta a Educação Contextualizada como aquela possível de ser descontextualizada e recontextualizada pelos sujeitos do processo. De fato, ela é uma relação dialética, mas que tem em seus entremeios a descolonização em voga. Da mesma forma, Oliveira e Reis (2017, p. 111) apontam que a educação para ter qualidade "precisa ser, entre outros fatores, contextualizada (ou seja, estar conectada à realidade dos sujeitos aprendentes) e descolonizada (das narrativas eurocêntricas, sexistas, classicistas, etc.)”. A Educação Contextualizada é, dessa forma, um ato também político.

Contextualizar, portanto, é esta operação mais complicada de descolonização. Será sempre tecer o movimento de uma rede que concentre o esforço em soerguer as questões "locais" e outras tantas questões silenciadas na narrativa oficial, ao status de "questões pertinentes" não por serem elas "locais" ou "marginais", mas por serem elas "pertinentes" e por representarem a devolução da "voz" aos que a tiveram usurpada, roubada, negada historicamente. (MARTINS, 2004, p. 34)

Contextualizar não é um fim, mas um meio que dá voz às minorias, que, neste caso, são aquelas que estão à margem da sociedade capitalistamente ascendida, aquelas que não tiveram acesso à educação escolar, aquelas que formam a EJA, por exemplo, cujo processo parte de uma falsa homogenia no processo de ensino. Embora a Educação Contextualizada discutida neste trabalho tenha surgido de uma discussão filosófica sobre a existência do homem no Semiárido Brasileiro para ajudá-lo a conviver com a condição climática da região em vez de combatê-la, isso não quer dizer que ela deva ser voltada às práticas rurais, como é reduzida. Esse conceito sustenta uma proposta de educação que é pragmática e significante para o estudante, principalmente aos que não compõem a classe hegemônica da sociedade, conforme Oliveira e Reis (2017) defendem.

Essa educação voltada para a realidade de educandos menos favorecidos vem a calhar 
com as políticas de educação desenvolvidas no período pós-ditatura no Brasil com a redemocratização do ensino. Assim, o acesso à educação pela classe popular proporcionou um novo olhar sobre a EJA, que, conforme Capucho (2012), após a Constituição de 1988, essa modalidade foi inserida com educação básica, portanto, um direito. Apesar disso, para essa autora, o acesso para este público foi negado no passado e é dificultado no presente, principalmente pelos espaços ainda ocupados para a prática escolar.

A Educação de Jovens e Adultos, diferentemente da educação de crianças e adolescentes, se efetiva em diferentes espaços/tempos. Os cenários são múltiplos e na maioria das vezes precários, em escolas, empresas, templos religiosos, penitenciárias, unidades rurais, ocupações urbanas, hospitais, apenas os espaços mais comuns. (CAPUCHO, 2012, p. 65)

Diante disso, percebe-se a realidade que o ensino para jovens e adultos tem no Brasil, e o fato de os alunos de EJA serem de contextos tão diversos aumenta ainda mais a necessidade de que também as práticas pedagógicas sejam diversificadas, adaptadas à realidade deles (FREIRE, 1967; CAPUCHO, 2012). "Esse campo [a EJA] exige de seus(suas) profissionais um olhar diferenciado para as necessidades de aprendizagem dos diferentes públicos presentes em sala de aula, formulação de propostas de políticas pedagógicas flexíveis aos diferentes contextos nos quais se efetiva a prática" (CAPUCHO, 2012, p. 66). Nota-se, portanto, que a prática pedagógica na modalidade em questão e os postulados da Educação Contextualizada estão intimamente ligados, pois o protagonismo e a condição histórico-cultural do estudante está sendo considerada, e a pertinência das realidades socialmente desprestigiadas estão sendo consideradas.

Os estudantes ao entrarem na escola devem ser considerados agentes de sua própria formação, pois suas realidades são os trilhos pedagógicos relevantes no processo de ensino. A partir disso, as práticas escolares devem coerentes ao estudantes e passíveis de ressignificação, dando-lhes acesso ao conhecimento socialmente requerido e que os auxiliem a usufruir de espaços e condições que foram deles suprimidos. Essa ação centrada na Educação Contextualizada permitirá que o direito à educação seja mantido e que as múltiplas histórias e culturas igualmente valorizadas.

\section{Material e Métodos}

Esta pesquisa tem abordagem qualitativa-descritiva, pois o objetivo principal foi identificar a relação entre as práticas de letramento escolar (KLEIMAN, 1995) e a conexão com os fundamentos da Educação Contextualizada (MARTINS, 2007). 0 viés qualitativo está amparado em Lüdke e André (1986, p. 13), pois “envolve a obtenção de dados descritivos, obtidos no contato direto do pesquisador com a situação estudada, enfatiza mais o processo de que o produto e se 
preocupa em retratar a perspectiva dos participantes". Nesse sentido, o viés descritivo encaixase e converge para a realização das técnicas de procedimento. Marconi e Lakatos (1999, p. 22) apresenta este último viés como sendo "descrição, registro, análise e interpretação dos fenômenos atuais, objetivando o seu funcionamento no presente". Tendo em vista a necessidade de descrição do objetivo norteador, é pertinente esse elo.

A pesquisa foi realizada a partir de um roteiro de método etnográfico (LÓPEZ, 1999), cuja intenção principal foi observar práticas de leitura e escrita em sala de aula sob a perspectiva pedagógica da educação contextualiza. Tal método foi seguido com a utilização das seguintes técnicas de procedimentos: observação participante pelo período de 30 dias, registro das ações no diário de bordo, gravação de aula em aplicativo de smartphone e entrevistas informais com discentes e docente, cujos dados foram tratados para uso neste artigo. Vale salientar que o método etnográfico é originário da Antropologia e, portanto, requer fenômenos humanos como centro das investigações.

A proposta de um estudo antropológico e etnográfico requer contato em tempo estendido, conforme Geertz (2008) aponta. Entretanto, este trabalho seguiu as características do método etnográfico, o que requer, conforme López (1999), a adoção do pesquisador ao caráter holístico do método, se envolvendo na natureza das pessoas envolvidas, lançando-se na perspectiva indutiva para relação com as teorias, estudando o caráter fenomenológico na evidência dos significados sociais e sem emitir juízo de valor.

Esta pesquisa foi realizada no microcosmo de uma escola na zona rural de Petrolina/PE, localizada no Projeto de Irrigação Senador Nilo Coelho, na zona Norte do município, que atendia cerca de 550 alunos nos turnos matutino, vespertino e noturno. A turma escolhida para a investigação era da modalidade de Educação de Jovens e Adultos e estavam na quarta fase do segundo segmento.

Neste trabalho, embora o foco seja a descrição densa do fenômeno observado, serão expostas algumas análises das entrevistas informais realizadas com três estudantes selecionados e alguns posicionamentos do docente de Língua Portuguesa da turma escolhida. A seleção desses estudantes foi mediada pelo convite feito em espaço aberto após o período de observação, haja vista a familiaridade dos estudantes com o pesquisador. Acrescenta-se que com vistas aos procedimentos éticos de anonimato e confidencialidade creditados neste estudo, os nomes dos envolvidos na pesquisa foram alterados, pois o foco, neste caso, está na realidade da investigação e na descrição das práticas de letramento escolar e suas nuances com a educação contextualizada.

\section{Resultados e Discussão}

Observando as características da comunidade escolhida para a investigação, emerge o pensamento de Freire (1967) que diz que pensar a educação é pensar o lugar. Dessa forma, ainda 
LIMA, F. R. S.

Educação contextualizada no letramento escolar: um olhar sobre a EJA

que as teorias e métodos possam ser replicadas em outro lugar, foi daquele espaço que se emergiram determinados resultados e reflexões. Com isso, torna-se relevante compreender quem são os agentes que humanizam a instituição selecionada.

Os professores que trabalham nessa escola são, em sua maioria, moradores da zona urbana de Petrolina/PE, mas dois deles residem na cidade de Juazeiro/BA, e um é morador local da comunidade. Essa condição é relatada porque a interação entre professor-comunidade já é iniciada na própria "van" que transportam os transeuntes. Do ponto de vista do conhecimento das realidades, percebe-se que os professores são de locais diferentes, portanto, é necessária uma imersão também na vivência local pelo docentes.

Adentrando o espaço escolar, a escola é organizada originalmente conforme o padrão estadual para escolas rurais de Pernambuco: pátio pequeno, cerca de $50 \mathrm{~m}^{2}$, ao centro, e com as salas de aula e as salas administrativas em volta desse espaço. Não há refeitório, não há espaços de lazer, não há bancos de descanso, apenas o pátio. No ano de 2012, a escola passou por uma reforma de ampliação, haja vista a quantidade de alunos que se matricularam. Isso reflete que a comunidade rural também cresceu, algo que deve ser considerado para as práticas escolares.

A turma focalizada tinha cerca de 30 estudantes e frequentavam o turno noturno. Essa realidade já é uma grande diferença em relação à pedagogia envolvida. Esse público é geralmente formado por pessoas que não tiveram acesso à educação escolar na faixa etária ideal estipulada na legislação, por trabalho, por problemas familiares, ou simplesmente porque não tinham escola disponível quando jovens. Não é incomum encontrar pessoas que na década de 50, 60 e 70 tiveram que percorrer léguas para conseguir estudar na escola ou ter acesso às práticas escolares, ainda que informais, conforme os espaços usado para o ensino apontados por Capucho (2012).

A seguir, na Tabela 1, serão apresentadas características dos estudantes pesquisados. Essas informações são relevantes para que se possa situar os discursos que surgirão no decorrer da descrição e análise. Além das informações de identificação (gênero, idade, local da residência, estado civil) foram questionados acerca da relação com o trabalho e com a religião, como: "Você trabalha? Com o quê?" e "Frequenta algum espaço religioso? Igrejas, terreiros, centros, por exemplo?". Essas informações foram ajustadas no espaço abaixo.

Tabela 1 - Caracterização dos sujeitos pesquisados

\begin{tabular}{c|c|c|c|c|c|c}
\hline Estudante & Idade & Gênero & $\begin{array}{c}\text { Estado } \\
\text { Civil }\end{array}$ & $\begin{array}{c}\text { Espaço } \\
\text { religioso }\end{array}$ & Atividades laborais & $\begin{array}{c}\text { Local de } \\
\text { residência }\end{array}$ \\
\hline E1 & 26 & Masc. & Casado & Católico & Trabalhador rural/geral & Lote \\
\hline E2 & 19 & Masc. & Solteiro & Católico & Trabalhador rural/geral & Vila \\
\hline
\end{tabular}




\begin{tabular}{c|c|c|c|c|c|c}
\hline E3 & 18 & Fem. & Casada & Católica & Revendedora de cosméticos & Lote \\
\hline
\end{tabular}

Fonte: Elaborado pelo autor (2019).

Sobre o docente investigado, ele não tem formação para ensino de EJA e é professor temporário. Capucho (2012) revela que essa realidade de rotatividade, comum aos profissionais temporários, fragilizam a educação, além dessa falta de formação específica para prática pedagógica para determinada modalidades.

Os estudantes colaboradores da pesquisa são de fato pessoas que sofreram algum atraso na vida escolar, reflexo de uma restrição social e econômica (CAPUCHO, 2012). Mas esse retardamento não cessou a vontade de construir-se nesse espaço. Percebe-se que o desejo em estar na escola e, de fato, ser letrado nessas práticas é o grande desejo. Ao serem questionados o porquê de virem à escola, deram as seguintes respostas (estas respostas foram transcritas da mesma maneira que o informante concedeu, sem ajustes ortográficos ou intervenções):

E1: "Pra pode estuda e le e escreve."

E2: "Trabalar e depois entrar na faculdade."

E3: "Eu venho porque gosto de estuda aqui, gosto dos professor. Eu quero conseguir um emprego bom."

Com tais depoimentos, infere-se que E1 é um estudante que tem seu objetivo delineado pelo domínio da prática de leitura e escrita. Essa assertiva pode ser comprovada durante toda a observação. Ele sendo um dos mais velhos da turma naqueles dias, aparentava tornar-se adolescente. Era uma alegria sem tamanho quando adentrava na escola. A esposa, mais jovem, que legalmente era noiva, pois como eles mesmos disseram "não têm o papel que diz que é casado", também estudava na mesma sala e o apoiava nas atividades.

A felicidade de $\mathrm{E} 1 \mathrm{em}$ mostrar os afazeres escolares aos professores - e até ao pesquisador - era um momento de grande euforia. A disciplina de Língua Portuguesa era a que ele mais se interessava. Essa afirmação era cotidianamente ratificada: pelo chamamento que fazia ao professor convidando-o a ir à sala; pela pressa em conseguir seus "pontos" e seu "visto"; pela participação e interação nas histórias de vida que relatava; e entre muitos outros eventos, os quais enchiam os olhos daqueles que ali conviviam. A seguir, segue uma transcrição de um dos momentos de diálogo entre o professor e o aluno, e logo depois um diálogo entre o aluno e o pesquisador (nesta transcrição houve a manutenção da oralidade na escrita):

E1: (indo até outra sala) Profissô, profissô! Bora, homi! Sai dessa sala logo! É com nóis a aula agora! [ruídos]

Professor: (sorrindo) Vamos, homem! Deixe só eu apagar o quadro e chego lá já.

E1: Tá bom. Eu já fiz as tarefa, viu? Ela me ajudou. (apontando para a esposa)

$[\ldots]$ 
E1: Ei, você vai dar aula pra nóis por enquanto o professor num vem? [dirigindo-se ao pesquisador]

Pesquisador: Hoje não, mas quem sabe um dia, né?

Em conversas mais informais, E1 relatou que foram muitos anos tentando estudar, mas sempre a necessidade de se alimentar - e também a família - foi prioridade. A partir desses dados, é possível traçar e evidenciar a negligência social que as políticas de educação não corrigem. A educação escolar, no caso do E1, é um diferencial e chega a ser até o seu objetivo de vida, ao qual, mesmo com todas as limitações de acesso e ritmo de aprendizagem muito subjetivo, deposita-se esperança de inserção em uma comunidade letrada. São essas conquistas que fazem o sentido do letramento ser materializado.

O perfil do E2 não difere drasticamente do estudante anterior. O trabalho, nesse caso, vem antes da continuação dos estudos mais específicos. Esse estudante, portanto, almeja terminar o Ensino Básico, trabalhar e, só depois, entrar na faculdade. O labor para os que formam as turmas de EJA é o primeiro plano; algo que fundamenta cada vez mais o objetivo do programa criado no século XX, com outras diretrizes, mas já com atenção a esse público com foco no trabalho.

Esse estudante, na época pesquisada, não tinha uma boa assiduidade. Em conversa com a turma, ele relatou que estava saindo muito tarde do trabalho. As aulas tinham início às $18 \mathrm{~h} 40 \mathrm{~min}$ e seguiam até às $22 \mathrm{~h}$. 0 estudante sempre chegava no segundo horário com a justificativa do trabalho, algo que é possível relacionar com as atividades laborais na lavoura. Em um determinado período, o professor perguntou-lhe se estava na safra - período de muita colheita - e a resposta foi positiva. Esse argumento é algo que é bastante considerado na educação de estudantes trabalhadores, pois vários fatores interferem na situação de ensino-aprendizagem (atraso, cansaço, fome, fadiga, faltas), principalmente quando o trabalho é na agricultura, que demanda enorme esforço físico.

O perfil da E3 tem também o trabalho como eixo, entretanto, o desejo pela educação escolar vem a partir da empatia com os professores daquela escola. Nesse quesito, o "gosto de estudar aqui" tem peso relevante, sentido esse de compreensão da importância empática que a escola tem com o estudante. 0 aprendizado dela vem a partir das relações de afeto que foram construídas naquele espaço que muitas vezes é traduzido só em números, notas e conceitos, mas, neste caso, há sentimentos valorizados.

A necessidade de um bom emprego, assim como o E2, está presente no discurso dessa estudante. Um bom emprego, ao que parece, é aquele que há menos exposição ao Sol, menos trabalho braçal e com um retorno financeiro considerável. Ela vê a escola como um caminho que a levará para funções e lugares mais lucrativos, condição essa que não é descartada na sociedade atual letrada e competitiva.

Diante de tais descrições, duas aulas foram selecionadas para a investigação do fenômeno proposto, a saber, o elo entre a educação contextualizada nas práticas de letramento escolar. A prática de letramento que será analisada envolveu, entre outros aspectos do letramento escolar, 
a concepção inicial de leitura e escrita autônomas. Apesar disso, as práticas sociais foram incorporadas no processo, relevantes para a contextualização.

A esfera escolar exige um trâmite dialógico intenso. Foi percebido que o professor discorria seu planejamento em base bakhtiniana, tal qual os métodos freirianos (FREIRE, 1967), mesmo as aulas tendo como objetivo final a prática da leitura e da escrita. É importante considerar que o diálogo, nesse caso, não é restrito à fala, mas também engloba as práticas escritas, a linguagem corporal e a condição afetiva construída e demonstrada.

A primeira aula em questão foi de apresentação do texto. 0 professor havia pedido na aula anterior que todos trouxessem o material, referindo-se ao livro, pois alguns estavam sem ele. Um adendo importante é saber que o livro didático é um diferencial para esse público e para muitas realidades da escola pública, porém, de acordo com o observado e em conversa com a equipe docente da escola - em momentos desmonitorados da pesquisa, como o cafezinho antes das aulas - a luta pelos direitos do estudantes da EJA, assim como os das outras modalidades de ensino, era constante. 0 livro foi, neste caso, uma conquista para o apoio pedagógico. A proposta docente foi, então, utilizar o conto Por um pé de feijão, de Antônio Torres, que está no livro EJA Moderna: educação de jovens e adultos, da editora Moderna.

0 texto é facilmente encontrado em sítios eletrônicos, cujo enredo é desenvolvido em torno de uma relação familiar de área rural que tem a plantação com promessa de grande colheita, mas teve o sonho interrompido por um incêndio. 0 docente pediu primeiramente para que os estudantes olhassem o texto e falassem o que lhes viesse. Posicionamentos em relação ao texto como "tudo disso", "é grande”, "tem nem desenho" surgiram, mas o E1, rebatendo as interpretações enviesadas, falou para os estudantes:

E1: Olhe o nome feijão! Ninguém sabe o que é feijão? Precisa de desenho não, professor, todo mundo sabe o que é.

Com essa inciativa, é notório que E1 fez a decodificação da palavra "feijão" no título, compreendeu o sentido do lexema e deu-lhe sentido. 0 estudante associou prontamente o signo linguístico com seu significante e compartilhou o seu significado com a turma. Essa é uma ação que envolve não somente os aspectos textuais, mas também os discursivos, os quais ganham proporção no decorrer da prática nessa esfera escolar. Essa é uma ação de leitura, a qual permitiu o estudante se posicionar na sala diante da situação de aprendizado, logo, é um caminho para o letramento.

O docente iniciou a leitura fazendo uma relação com as atividades cotidianas do estudantes trabalhadores da lavoura. A partir disso, o diálogo surgiu (AA refere-se a um aluno da turma não identificado):

Professor: Quem aqui já plantou feijão?

E2: Meu avô tem na casa dele. 
LIMA, F. R. S.

Educação contextualizada no letramento escolar: um olhar sobre a EJA

E3: Eu nunca.

AA: Pra quê?

E1: Oxen! No mercado tem.

[...]

AA: Na aula de ciências a gente já botou no copo pra crescer.

E3: Ah, foi! Eu tenho o meu, mas morreu. (risos)

Ação de plantar feijão pode ser uma ação comum para quem mora em zona rural, mas muita gente não tem o contato com o processo. Hoje, a urbanização e a logística propiciam algumas ocorrências que tornam mais cômoda a aquisição de determinados produtos já em fase de consumo. No diálogo acima, percebe-se que por mais próximos que estejam os sujeitos da zona rural, não significa que as práticas rurais estejam materializadas na vida deles. Isso reflete o que Oliveira e Reis (2017) e Martins (2004) atentam para um ensino para além da educação rural. Logo, esse conceito de contextualização tem tomado forma não localista. A ação do professor em inquirir quem já plantou não é uma relação contextualizada e não ajuda no letramento, porém quando a estudante refere-se a outras práticas, isso significa que ela já conseguiu descontextualizar o que foi dito pelo docente e recontextualizar nas práticas subjetivas. A partir disso, foi possível estimular que as outras realidades culturais se despertassem para o processo.

A educação freireana propõe que sejam feitas ações que estejam presentes nas culturas dos educandos, até porque, são contextos muito diversos, e na realidade de EJA, esses caminhos tomam necessidades distintas (CAPUCHO, 2012). Entende-se que a pergunta do professor foi oportuna, mas a hipótese de se ter um reconhecimento majoritário da prática de plantar feijão não é algo que deveria ser construído. A proposta da educação contextualizada é próxima do pensamento de Freire (1967), pois alimenta o sentido de significação dentro da prática escolar.

A prática escolar, porém, não é algo que estanque à leitura e escrita codificada. A aula de ciências relatada por E3 é um exemplo de uma prática escolar atrelada às fases de um vegetal. Como exposto, não se pode afirmar que 0 ato do feijão seja uma prática de educação contextualizada, mas que a prática escolar de uma experiência didática aproximou os estudantes do processo de uma plantação que thes é conhecida. Usando essa referência o professor relatou em uma conversa:

Pesquisador: Quando a aluna falou do feijão que nunca tinha plantado, foi diferente, né?

Professor: Então, eu já esperava essa reposta. Não é porque estamos na zona rural que eles têm que ser trabalhador rural. Por isso que perguntei se alguém tinha plantado feijão. Alguma coisa ia sair! Nem que fosse da aula de ciências, que foi trabalhado no início da unidade pela outra professora.

No seguimento da aula, o professor procurou refletir acerca do tempo que um feijão demorava para começar a produzir e o quão prejudicial seria se alguém precisasse do dinheiro da venda daquela safra, mas não pudesse utilizar. Identificou-se nesse processo uma técnica de leitura colaborativa que foi seguida durante toda a aula. Mesmo o objetivo final sendo a leitura e a escrita, essas ações não se encerram nelas mesmas. 0 docente pediu para que os estudantes 
LIMA, F. R. S.

Educação contextualizada no letramento escolar: um olhar sobre a EJA

lessem silenciosamente o texto e que o chamasse se caso surgisse alguma dúvida na leitura. Um episódio nessa ação teve destaque durante a prática:

E3: [...] o que é "tripas saindo pela boca"?

Professor: Você nunca ouviu esse ditado? "Fulano está com as tripa saindo pela boca"?

AA: Esbaforido!

E3: O quê?

E1: Cansado e não aguenta mais correr (gestualizando o cansaço).

E3: Ah! Igual quando a gente tá indo pegar o carro! Entendi! (risos) Lá em São Paulo a gente usa "cansado" mesmo.

Essa comunicação entre os alunos denota uma relação contextual diferente. Nem sempre a contextualização de conteúdo é o tratamento com perspectivas locais. A abstração do conteúdo é necessária para que seja recontextualizado pelo outro interagente da ação (MARTINS, 2004). As concepções de educação contextualizada não devem ser restritas ao local, mas a uma possibilidade de subjetividade de cada estudante (OLIVEIRA; REIS, 2017; MARTINS, 2004).

Fazer esse processo em uma sala de aula com tantas culturas é extremamente conflituoso, mas o conflito não é uma condição avessa à educação. A estudante E3 é uma migrante, portanto, tem conhecimentos prévios e culturas especificas que thes são compreensíveis. 0 ditado popular, por exemplo, não era de sua cultura, mas hoje já faz parte do seu repertório. A condição dela estar no Semiárido Brasileiro não exige uma necessidade de conhecimento sobre o lugar em que mora. A educação contextualizada é antes de tudo uma voz da organização civil em prol do espaço identitário que foi durante muito tempo tomado como inóspito (MARTINS, 2004). Entender que essa concepção partiu desse lugar é importante, que é passível de translocações, mas a origem deve ser considerada (FREIRE, 1967).

O evento de letramento que estava sendo realizado foi um subsídio para a prática letrada e teve uma necessária contextualização para a devida compreensão. Isto é, o ato de ler um texto no livro didático foi realizado dentro do momento da sala de aula, mas devido a não compreensão de um discurso comum para a outra realidade, fez-se necessária a intervenção que recolocasse a ideia em voga em uma situação dentro da pragmática àquele outro estudante. 0 professor nesse caso, facilitou a compreensão para os estudantes, porém os verdadeiros agentes contextualizadores foram os estudantes, que já compreendem a relações culturais diversas naquele ambiente.

Diante do exposto, nota-se uma relação entre a prática letrada e a educação contextualizada. Na segunda aula, cujo foco foi direcionado às práticas de escrita, um estudante escreveu a expressão "torado", referindo ao verbo "torrar" em uma questão do exercício. A estudante E3, que estava ao lado, pediu o caderno do colega de classe e elaborou duas frases. A primeira dizia "Café torrado é gostoso" e a segunda "O carro de Araújo torou no meio". Neste momento, ela leu em voz alta e o professor foi verificar o que estava ocorrendo e auxiliá-la.

Professor: 0 que houve, gente? Quem torou quem? 
E3: Não, professor, é que ela escreveu "torado" no lugar de "torrado", mas ela queria dizer que o feijão torrou, aí eu tô dizeno porque quando a gente não entende uma palavra, o professor vai e coloca no quadro e explica o que ela diz dos dois jeitos, né? Tudo tem dois jeitos.

Essa reação da estudante em também ser um agente de letramento possibilitou inúmeras reflexões. A primeira delas é em relação à prática ortográfica a partir da palavra escrita e da palavra intencionalizada. E3 contextualizou, no sentido textual e no sentido semântico-pragmático, as palavras que estavam sendo requeridas em "Café torrado é gostoso" e "O carro de Araújo torou no meio", tanto do ponto ortográfico quanto do semântico-pragmático. A outra é o indício de variação ou ambiguidade trazido pelo desvio ortográfico para o termo adequado àquele contexto. Essa última ação é reflexo da prática do docente que, em vários momentos das aulas, apontava traços sociolinguísticos em palavras e o sentido polissêmico das expressões a partir dos contextos e culturas, como as palavras "teia" e "telha" discutidas em uma aula anterior. Todas essas ações, na perspectiva do letramento (KLEIMAN, 1995), promovem um posicionar-se socialmente, principalmente na demonstração de sua língua cultura e no uso da linguagem a partir da situação discursiva.

Com esses episódios, torna-se coerente afirmar que a prática de letramento escolar é aprimorada quando há prática de uma educação contextualizada e pragmática. Além disso, é evidente que tais eventos pedagógicos são constituídos e fortificados na interação entre os agentes, seja professor, seja estudante. A contextualização enviesa o letramento tornando-o coerente e apto ao uso consciente fora dos espaços escolares. A educação brasileira, portanto, tem exigido uma reflexão mais próxima da educação intercultural e com práticas aparentes.

\section{Conclusões}

A educação escolar é um direito de todos os brasileiros, mesmo nos mais longínquos espaços. Sabe-se que há uma deficiência de acesso à escola e principalmente se a comunidade for de zona rural. Em uma sala de aula é indiscutível a pluralidade cultural e linguística, e essa condição exige cada vez mais da prática de ensino. A EJA, especialmente, traz ideologias e filosofias para o espaço pedagógico, pois têm pessoas que já carregam consigo essa subjetividade, algo que deve ser aproveitado e compartilhado em sala de aula.

As discussões sobre o letramento escolar como algo além do ensino decodificador são, portanto, relevantes. Os debates sobre a contextualização, por sua vez, tornam-se pertinentes, pois o contexto é subjetivo; logo, na sala de aula, em condição plural, é inconcebível a padronização baseada em uma cultura específica. Esta pesquisa pode comprovar que a educação contextualizada, não necessariamente localizada, possibilita uma contextualização aparente e significativa e auxiliando na prática do letramento na escola. O viés da educação contextualizada localizada também é valorizado como apoio às práticas, desde que aconteçam as relações interculturais e os sujeitos se permitam interagir. 
LIMA, F. R. S.

Educação contextualizada no letramento escolar: um olhar sobre a EJA

\section{Referências}

BORTONI-RICARDO, S. M. O professor pesquisador: introdução à pesquisa qualitativa. São Paulo: Parábola Editorial, 2008.

CAPUCHO, V. Educação de jovens e adultos: prática pedagógica e fortalecimento da cidadania. São Paulo: Cortez, 2012.

FREIRE, P. Educação como prática da liberdade. Rio de Janeiro: Paz e Terra, 1967.

FREIRE, P. Pedagogia da autonomia: saberes necessários à prática educativa. $22^{\mathrm{a}}$ ed. Paz e Terra, 2002.

GEERTZ, C. A interpretação das culturas. Rio de Janeiro, $1^{\mathrm{a}}$ Ed, $13^{\mathrm{a}}$ reimpressão, LTC, 2008.

KLEIMAN, A. B. Modelos de letramento e as práticas de alfabetização na escola. In: KLEIMAN, A. B. (Org). Os significados do letramento: uma nova perspectiva sobre a prática social da escrita. Campinas-SP: Mercado de Letras, 2008, p. 15-61.

LÓPEZ, G. L. O método etnográfico como um paradigma científico e sua aplicação na pesquisa. Textura, Canoas, V. 1, n. 1, p. 45-50, 1999. Disponível em: www.periodicos.ulbra.br/index.php/txra/article/download/660/470. Acesso em: 23 Set. 2019.

LÜDKE, M.; ANDRÉ, M. E. D. A. Pesquisa em educação: abordagens qualitativas. São Paulo: EPU, 1986.

MARCONI, M. A.; LAKATOS, E. M. Técnica de pesquisa. 7.ed. São Paulo: Atlas, 2008

OLIVEIRA, R. R.; REIS, E. S. Entre o texto e o contexto: os gêneros textuais nos livros didáticos "conhecendo o semiárido 1 e 2" para a aprendizagem contextualizada. Linguagens, Educação e Sociedade, Ano 22, n. 37, jul./dez, p. 110-131, 2017. Disponível em https://revistas.ufpi.br/index.php/lingedusoc/article/view/7579/pdf. Acessado em 21/07/2019.

MARTINS, J. S. Anotações em torno do conceito de educação para a convivência com o Semiárido. In: Educação para a convivência com o semiárido. Juazeiro: RESAB, 2004, p. 29-52.

SAVIANI, D. Escola e democracia: teorias da evolução, curvatura da vara, onze teses sobre educação e política. $8^{\mathrm{a}}$ ed. São Paulo: Cortez, 1985.

SOARES, M. Linguagem e escola: uma perspectiva social. 16ª ed. São Paulo: Ática, 1999. 